\title{
Land Engineering Discipline Research
}

\author{
Cheng Jie ${ }^{1,2,3,4, \text { a }}$, Han Jichang ${ }^{1,2,3,4, b, *}$, Sun Zenghui ${ }^{1,2,3,4, c}$ \\ ${ }^{1}$ ShaanXi Province Land Engineering Construction Group, Xi'an 710075, China; \\ ${ }^{2}$ Key Laboratory of Degraded and Unused Land Consolidation Engineering, the Ministry of Land and \\ Resources of China, Xi'an 710075, China; \\ ${ }^{3}$ Institute of Land Engineering and Technology, Shaanxi Provincial Land Engineering Construction Group \\ Co., Ltd. Xi'an 710075, China; \\ ${ }^{4}$ Shaanxi Provincial Land Consolidation Engineering Technology Research Center, Xi'an 710075, China. \\ a568761241@qq.com, b2100653101@qq.com, ${ }^{\text {c2 } 249475181 @ q q . c o m ~}$ \\ *corresponding author
}

Keywords: land engineering; discipline; research object; research content; discipline system.

\begin{abstract}
Discipline is very important to industry development. At present, land engineering had been partially established. To speed up and improve the land engineering discipline, this paper discussed the research object, research connotation, research core and land engineering disciplines of Land Engineering. (1) The land (including the land with resource attributes, the land with problems and the land with contradiction between supply and demand) was the unique research object for land engineering. (2) The connotation of land engineering discipline was related to the study object. The main study object was soil organic reconstruction, which served for ecological land. (3) Discipline system of land engineering included land information engineering, land use protections and land reclamations. Acceleration of the construction of land engineering discipline is needed to provide scientific theoretical support to the development of land engineering and to ensure the sustainable use of ecological land.
\end{abstract}

\section{Introduction}

Since the beginning of human cultivation and settlement, the concept of land was generated. The land is the foundation of human beings, whose importance is self-evident. However, with rapid development of the economy, society and culture, especially the acceleration of industrialization and urbanization, human beings have gradually expanded the scope of land utilization. Land is the basis of social and economic development. At present, land is scarce in supply while its social demand is boundlessly increasing. The contradiction land supply and social demand has been aggravated, which has become a major "bottleneck" that inhibits the growth of the national economy and the development of harmonious society In particular, around 2020, china will face new problems of 300 million people including the elderly, migrant and landless people, respectively. The land problems will deteriorate and become more complicated. In addition, the shortage of talents in the land industry and the incomplete the discipline system led to the lack of systematic theory and technology to solve the land problem. There is no comprehensive technical regulation and standard system to guide the implementation of land remediation. It is difficult to meet the needs of the real development of land, merely relying on macro-strategy and planning [1]. Therefore, the discipline of land engineering emerged in order to make use of the power of disciplines to study in depth various issues related to land, create ecological land, and resolve resource crises. At present, the discipline of land engineering is still at the initial stage of construction. Studies on discipline construction cannot be ignored. This article starts from the definition of disciplines, discusses the research object, connotation and discipline system of land engineering, and aims to improve the theoretical system of land engineering disciplines and speed up discipline construction work. At the same time, it has aroused widespread concern among 
colleagues in the discipline of land engineering and early construction of the discipline of land engineering as a first-class discipline.

\section{Discipline overview and discipline construction}

According to the definition of "Cihai", "Discipline" refers to an academic classification, a certain scientific field or a branch of science. According to the definition of "The national standard of classification and code in People's Republic of China of" (GB / T 13745-2009), discipline is a relatively independent knowledge system. The process of discipline formation includes creating experience through activities; accumulating and digesting experience; forming knowledge through thinking, introspection, comprehension, and abstract understanding. Knowledge is developed and applied to knowledge and further developed to a scientific level. These developing and evolving knowledge systems are divided into disciplines based on certain common characteristics. The division is based on five aspects including research object, research characteristics, research methods, derived sources of the discipline, and research objectives and goals [2]. The discipline is linked with knowledge and is an integrated concept of the natural sciences and social sciences. It is the foundation of scientific research and personnel training, and is also the foundation of social services and development. The discipline plays a decisive role in the development of the industry.

Discipline construction is a concept with richer connotations. Different scholars have different understandings of discipline construction. Different scholars have different understanding of discipline construction. Zhang proposed that discipline construction, which has completely penetrated into the development process of higher education, is an extensive system involving extensive reforms of existing organizational systems, raising the level of disciplines, personnel training, scientific research, and serving the society, expanding and creating human understanding objects and knowledge systems [3]. Liu thinks that discipline construction is a construction activity based on the academic nature of the discipline, including the discipline orientation, academic echelon construction, base construction and project construction. It is a comprehensive construction of organizations, systems, resource allocation and other related social system [4]. In general, discipline construction is a basic, systematic and comprehensive work. It is also a combination of teaching, scientific research and personnel training. Discipline construction includes: the constructions of discipline direction, academic team, scientific research, personnel training, academic exchanges and others; improving the level of discipline and personnel training quality through scientific research to promote the development of discipline, specialty and teaching; forming a systematic theoretical knowledge and guiding the development of the industry through discipline construction.

\section{Construction status of Land Engineering discipline}

Land use has a long history in China. We advocated learning from the Soviet Union as early as the 1950s and introduced land planning disciplines to carry out land-related researches in different disciplines such as politics, agronomy and economics. In 1980, the China Land Society was established and formally propose land science. Since then, a great deal of research has been carried out on land use, evaluation, planning, management and technology. There has been a growing demand for the construction of "land science" disciplines. In 2013, according to years of land engineering practice, Han et al. found that to solve the land problem, a comprehensive discipline integrating land resources investigation, evaluation, planning, development, renovation, utilization, and protection must be established. Therefore, they proposed the concept of land engineering discipline, which defined the land engineering as "the process of utilizing engineering means to solve the land problem, turning the unused land into usable land or utilizing the used land efficiently, and coordinating the harmonious development of human-land relationship". Land engineering refers to the field of land engineering in this section, or areas of basic theory, engineering and other research, and the law formed a theoretical system, and then used to regulate the use of human science to guide the use of land science[5]. 
Since its establishment, land engineering has received the strong support of academicians at home and abroad. In 2013, the first monograph "Introduction to Land Engineering" was published, which preliminarily proposed the system of land engineering disciplines, disciplines, research methods and so on. It laid the foundation and opening of the door to the discipline of land engineering [5]. In September 2015, Chang'an University and the Land Engineering Construction Group of Shaanxi province co-founded the first land engineering college in China. In March 2017, the Ministry of Education issued "the Notice on Publishing the Results of the Record and Examination and Approval of Undergraduate Majoring in Colleges and Universities in 2016” (Teach high [2017] No. 2), which approve Chang'an University and China University of Geosciences (Beijing) to set up a new land improvement program (undergraduate), indicating the formal incorporation of land remediation projects into the undergraduate sequence of national education. At present, the School of Land Engineering has begun to recruit students [6]. In addition, several representative works have been published, including "Principles of Land Engineering", "Foundation of Land Engineering" and "Land Engineering Practice". Among them, the "Principles of Land Engineering" clarified the existing theoretical basis for the support of land engineering research. The "Foundation of Land Engineering" introduced the core and depth of the research. The "Land Engineering Practice" pointed out the technical routes and methods for various types of land engineering research.

\section{4 .Research objects of Land Engineering}

Although the study of land disciplines started earlier and the discipline of land engineering has been initially established, its systematic theoretical research still lags behind the objective reality, which seriously affects the in-depth development of the actual work of the land. Therefore, further study of the discipline of land engineering is an urgent task. Pan et al. proposed in the "Research of Higher Education in Multi-disciplinary Perspectives" that the construction of a discipline requires not only a unique research object and a complete theoretical system, but also a unique research method [7]. The object of study is the core and soul of discipline construction. It is a discipline-specific research field that is irreplaceable. No matter what kind of academic work, we must first have certain research objects and grasp the research object is the key to discipline construction. Therefore, it must identify the unique research object firstly, and then develop into unique research content and discipline system of land engineering discipline.

The discipline of land engineering, as the name implies, is mainly the study of land discipline. In the "Cihai", the land has five definitions: one refers to the field and the soil; the second refers to territories and territory, the third is the region and the place; the fourth refers to measuring terrain; the last one refers to the name and guardianship and of the God. In general, the land is a natural complex that participates in human production activities. It is an important material basis for the survival and development of mankind. Recognizing the land in the discipline of land engineering is not a single natural element, but a land with a natural, social and economic complex. Therefore, based on the nature of the land and its important role in human development, the research object of land engineering is divided into lands with resources attributes, lands with human perspectives, and lands with certain problems including pollution and damaged land, degraded land, low standard farmland, and construction land.

\section{The Connotation and Core of Land Engineering}

The connotation of the subject research is closely related to the cognition of the research object. From the perspective of the research object, the research connotation of the discipline of land engineering must first be the study of the nature and characteristics of the land, the exploration of the resource characterizations of the land as the natural resource and the overall study of the characteristics of land as a natural complex and the laws of its development. Secondly, the research connotation of the discipline of land engineering is also the main contradictions and the interaction between the land supply and demand, which needs to be explored through the economic and social 
attributes of the land. Finally, the connotation of land engineering is researching methods, techniques and systems for studying land restoration and rehabilitation, quality improvement and sustainable utilization. From the epistemology, methodology to practice theory of a comprehensive study, with a view to rational distribution of land resources and land use, to maintain a more reasonable structure of land use and obtain the maximum functional benefits.

At present, with the rapid development of human society, the problems such as land pollution, land degradation and land destruction become increasingly prominent. The contradiction between the supply and development needs of land is the most important contradiction in the current period. Based on this understanding, the key link is the core of the land engineering research. Through the study of land at a certain depth, technical means such as replacement, compounding, and reconstitution provide the necessary conditions for carrying living things. The scope of the study is mainly defined from the surface to the first layer above the diving layer, vertically spanning from a few centimeters to several hundred meters. The object of service is an organic life. The research goal is to build life systems, through the soil nutrients, plant nutrition, microbial nutrition and other control to build an excellent crop growth environment and human living environment. Specifically, it includes the main body engineering such as organic reconstruction of soil, mechanical reconstruction, particle reconstruction, cross-section reconstruction and biochemical reconstruction, and also contains supporting projects such as water conservancy, roads, forest networks, distribution and aesthetic design. The organic reconstruction of land is the core of land engineering research, the foundation of clean land supply, the foundation of ecological civilization construction, and the means of human expanding the living space.

\section{Discipline System of Land Engineering}

After many years of engineering practice, a complete and systematic discipline of land engineering is formed, which are composed of land resources, land information, land remediation engineering and land use and protection. Land information engineering reveals the mechanism and law of the information map of the land organism through studying of the mechanism, mechanism and mechanism of energy, material and information exchange in the soil through the process of land use. With information engineering theory and technology as the mean, and with the purpose of use land sustainable, the land information service platform is constructed with the goal of land information services, providing theoretical and technical support for land engineering and sustainable land use. Land use and protection: Mainly for the purpose and behavior of different land use of mankind, to study the characteristics and evolution law of the best combination of land and land under the maximization of comprehensive benefits of land use, as well as the engineering measures of land organism protection and land use technical means to provide engineering and technical support for sustainable land use and suitable land ecological environment. Land reclamation project: The main goal of urban land consolidation, land reclamation, land consolidation, land development in land engineering technology, methods and engineering measures for the study to form a practical and practical series of land remediation supporting technology and method system, comprehensive enhance the ecological, social and economic benefits of land use. The construction of each land project can't be separated from the support of the discipline of land engineering. Land resources and land information, land remediation engineering, land use and protection study the land engineering from different directions. These three directions form a complete discipline system, Better use of engineering solutions to land problems.

\section{Conclusions}

The main purposes of the construction of land engineering discipline are providing theoretical guidance to industrial development, scientific guidance to the implementation of land policy, and disciplinary basis to the comprehensive development of land resources, and cultivating the basic knowledge and basic theory of land engineering., human intervention in the land will not come to an end as long as human beings existence. With the rapid increase of contradictions among 
resources, environment and population, the construction of land engineering discipline is more urgent. We hope that there are more land industry workers devoting to the construction of land engineering disciplines for improving professional settings, cultivating academic leaders and training more advanced applied engineering talents with the ability to engage in land engineering survey, planning, design, construction and management.

\section{Acknowledgments}

This work was supported by the Fundamental Research Funds for the Central University of Changan University (300102278502) and the Scientific Research Item of Shaanxi Provincial Land Engineering Construction Group (DJNY-2018-23).

\section{References}

[1] Liu, Y.,S. Integrated Land Research and Land Resources Engineering .Resources Science.2015,37(1):0001-0008. In Chinese.

[2] Meng, S.,R. Intuitive Thinking Theory. Nanning: Guangxi People's Publishing House, 2002.136. In Chinese.

[3] Zhang, K.,X. Research on Related Issues of Discipline Construction in Colleges and Universities .Journal of Economic and Social Development, 2005,3 (10): 206-208. In Chinese.

[4] Liu, K.,Y. Research on Some Relations in Discipline Construction in Universities. Helong Higher Education Research, 2005 (3): 99-101. In Chinese.

[5] Han, J.,C. Introduction to Land Engineering. Beijing: Science Press, 2013. In Chinese.

[6] Cheng, J. Han, J., C. Zhang, Y, et al. Discussion on the Land Engineering Disciplines from Land Situation. China Population Resources and Environment, 2017 (S1): 147-151. In Chinese.

[7] Pan, M.,Y. A Multidisciplinary Perspective on Higher Education [M]. Shanghai: Shanghai Education Press, 2001.4.2. In Chinese. 